Working Paper 9501

\title{
MORE ON THE DIFFERENCES BETWEEN REPORTED AND ACTUAL U.S. CENTRAL BANK FOREIGN EXCHANGE INTERVENTION
}

by William P. Osterberg and Rebecca Wetmore Humes

William P. Osterberg is an economist and Rebecca Wetmore Humes is an economic analyst at the Federal Reserve Bank. of Cleveland.

Working papers of the Federal Reserve Bank of Cleveland are preliminary materials circulated to stimulate discussion and critical comment. The views stated herein are those of the authors and not necessarily those of the Federal Reserve Bank of Cleveland or of the Board of Governors of the Federal Reserve System.

May 1995 


\begin{abstract}
It is unclear whether the distinction between U.S. foreign exchange intervention and newspaper reports of such activity is important. Dominguez and Frankel (1993) argue that unreported intervention has a weaker impact on the market. In this paper, we ask the empirical question: If intervention is reported (was actual), does it matter whether it occurred (was reported)? For a subsample for both the yen-to-dollar and Deutschemark-todollar exchange rates, we reject the hypothesis that the impact of intervention on the variance does not depend on whether it was reported. We also find that the sign of the impact depends on whether the intervention was reported. In addition, we uncover some evidence for impacts of false reports of intervention. We suggest that remaining concerns about these distinctions should be focused on the market microstructure surrounding the actual intervention operations.
\end{abstract}




\section{Introduction}

The release of official data on daily U.S. central bank foreign exchange operations has brought about an increase in the number of studies analyzing the impacts of intervention on the level and volatility of exchange rates. Prior to the release of such data, empirical studies of intervention relied on confidential daily data or on daily data culled from newspaper reports, or else opted to study intervention at lower frequencies using stock measures of private-sector holdings of government bonds denominated in different currencies. ${ }^{1}$

The overall finding of the empirical studies (see Dominguez and Frankel [1993] and Edison [1993] for summaries) is that if intervention affects exchange rates, it probably does so through a signaling, or expectations, channel. This channel implies that intervention conveys information to the market about future monetary policy. The literature has discussed a variety of conditions that may be required before such a policy can be effective. One issue that has not been addressed in much detail, however, is whether the accuracy of the market's information about intervention, or any implied asymmetry in the market's information, influences the efficacy of intervention. It is possible that the way in which the authorities intervene may play an important role in the outcome of intervention operations.

In this paper, we analyze the differential impacts of reported and actual U.S. intervention on the mean and conditional variance of the Deutschemark-to-dollar (DM/\$) and yen-to-dollar (Yen/\$) exchange rates. We utilize a GARCH framework to model the conditional variance, test for day-of-the-week effects, and then look for the impact of either reported or actual intervention. We report tests of the restrictions imposed by studies that 
utilize either actual intervention or reported intervention, namely, that 1) if intervention occurred, it doesn't matter whether it was reported, and 2) if intervention was reported, it doesn't matter whether it occurred. Somewhat surprisingly, once we have accounted for day-of-the-week effects, we find that only reported intervention has an impact over the full sample periods, and it is only on the variance of the yen-to-dollar exchange rate. In addition, the distinction between intervention that was not reported and intervention that was reported is significant for the conditional variance in a subsample for both exchange rates. Furthermore, we find some evidence that both false reports and missing reports of intervention occasionally affect exchange rates.

The paper is organized as follows: In the next section, we discuss related work and clarify the issues. In the second and third sections, we describe institutional factors and the data, respectively. Then, in the fourth section we present our empirical method. The fifth section presents and discusses the results of our empirical analysis, and the final section summarizes our findings and indicates what we believe are the remaining issues.

\section{Related Literature}

When analyzing daily U.S. intervention operations, it is conventional to use reported data if the intention is to focus on the signaling channel (the role of intervention in communicating the Federal Reserve's intentions regarding monetary policy), but to use actual data if the interpretation is to be in terms of portfolio balance. ${ }^{2}$ For example, if intervention signals monetary policy, a purchase of dollars may be interpreted as indicating that monetary policy will increase interest rates and thus raise the exchange value of the dollar. If portfolio balance is the mechanism, a purchase of dollars (if sterilized) forces the private sector to 
hold fewer dollar-denominated securities, which will require a lower expected rate of return on such securities, and thus a decrease in the risk premium. ${ }^{3}$ A handful of studies have now utilized both the reported and actual daily U.S. data. However, there has been little discussion of the relevance of the mechanism through which information about intervention is conveyed to the average trader.

Klein (1993) estimates the probability of intervention having occurred, given that it was reported in either The Wall Street Journal or The New York Times, and the probability of it having been reported, given that it occurred. His estimates are 88 and 72 percent, respectively. Dominguez and Frankel (1993) perform a sequential search of intervention news from three newspapers (The Wall Street Journal, Financial Times, and The New York Times) and analyze the impact of reported intervention that occurred and "secret" intervention (actual intervention that was not reported) on the exchange rate. They find that the impact of secret intervention is weaker than that of reported intervention, but is still significant. Dominguez (1993) analyzes the impact of reported and secret U.S. intervention on exchange rate volatility using a $\operatorname{GARCH}(1,1)$-student-t distribution. Hung (1991) also discusses the relative effectiveness of "discreet" and "overt" intervention. Osterberg and Wetmore Humes (1993) compare actual intervention to intervention reported in The Wall Street Journal and find that the difference between the two is not white noise.

\section{Institutional Considerations}

Consideration of the details of U.S. intervention operations is important for interpreting the estimated impacts of actual and reported intervention in studies of the efficacy of U.S. foreign exchange interventions. ${ }^{4}$ Data on U.S. intervention operations are 
not released until one year has passed. Intervention operations at the Federal Reserve Bank of New York are accomplished via either commercial banks or brokers. If commercial banks are utilized, they are expected to notify the wire services that the Fed is in the market immediately after the order has been placed. However, if the Fed contacts brokers directly, notification is not expected, and the Fed's presence in the market will not be automatically revealed. ${ }^{5}$ Humpage (1994) indicates that since the mid-1980s, the Federal Reserve has generally relied more on commercial banks than on brokers.

Three uncertainties complicate the interpretation of newspaper reports of intervention. First, it is not clear how often the Fed utilizes brokers directly. Second, it is not clear how much time passes between the call from the Fed and the average trader learning of the intervention. Third, it is not clear how the newspapers obtain their information about intervention activity. Klein (1993) cites one source as indicating that traders generally inform the newspapers of intervention activity. However, another source told us of the existence of "information brokers" who collect information about market developments through informal channels, then disseminate it to paying customers. Thus, it is not clear if reported intervention corresponds to that accomplished via commercial banks, or even to the information of the average trader.

Newspaper reports about intervention are often vague. Among the ambiguities are the following: 1) specific currencies are often not mentioned; 2) reports may be delayed, implying that segments of the market may not have learned of the intervention quickly; 3) one country may intervene on behalf of another, but it is not clear how the market interprets such reports; and 4) intervention may have been rumored but then discounted. 
This creates a dilemma when coding newspaper reports of intervention activity. Assuming that news of actual intervention reaches the average trader (unless the intervention utilizes brokers) may imply a relatively liberal coding. On the other hand, in order to focus on the impact of any asymmetry in the market's information about intervention, one may wish to employ more conservative coding conventions.

\section{Data}

The official daily U.S. intervention data were supplied to us by the Board of Governors of the Federal Reserve System. These data are now available to the public with a one-year lag. The data are given as the daily net purchases of the U.S. dollar vis-a-vis the Deutschemark or yen. The exchange rate data were supplied by the Federal Reserve Bank of New York and are quoted as of 10:00 a.m. New York time. We culled the reported intervention series from The Wall Street Journal, as described in detail in Osterberg and Wetmore Humes (1993).

It is worth emphasizing that other researchers have utilized different series on reported intervention. Dominguez and Frankel (1993) searched The Wall Street Journal, Financial Times, and The New York Times sequentially for reports of intervention. Klein (1993) utilizes reports from The Wall Street Journal and The New York Times. Like us, Bonser-Neal and Tanner rely on The Wall Street Journal.

Our data include only specific reports of U.S. dollar intervention as published in the foreign exchange column of The Wall Street Journal. Compared to other compilations of reported intervention, our tabulations are conservative. Numerous judgments must be made in coding newspaper reports. For example, we do not include reports of U.S. intervention 
unless they specified the foreign currency being bought or sold. Also excluded are reports of intervention that did not appear until later than the next working day. Other aspects of the data collection procedure are discussed in Osterberg and Wetmore Humes (1993). It is not clear how other researchers dealt with these issues.

The sample period is August 6, 1985 through September 5, 1991 for the DM/\$, and August 5, 1985 through October 4, 1991 for the Yen $/ \$ .^{6}$ However, since previous investigations have noted that the goals of intervention vary from one period to another (Humpage and Osterberg [1992], Dominguez and Frankel [1993]), we estimated our model for the following subperiods: February 23 to October 18, 1987, October 19, 1987 to February 19, 1990, and February 20, 1990 to September 5, 1991 (DM/\$) or October 4, 1991 $(\text { Yen } / \$)^{7}$

\section{Methodological Approach}

Ideally, we would utilize intradaily data identifying the counterparties, the time of intervention, quotes surrounding the intervention, wire service entries, and newspaper reports. However, the identities of the counterparties are not available, and the other information is relatively costly to obtain, except for short sample periods. Consequently, we opt for a more modest approach, albeit one that has the advantage of being directly comparable to previous empirical investigations. In order to focus on the relevance of asymmetry in the market's information about intervention, we test two null hypotheses:

H1: If intervention occurred, it does not matter if it was reported.

H2: If intervention was reported, it does not matter if it occurred.

Failure to reject $\mathrm{H} 1$ might lessen concerns that the efficacy of intervention is 
somehow related to the way in which information about intervention is transmitted to (or through) the market. One could interpret failure to reject $\mathrm{H} 1(\mathrm{H} 2)$, combined with rejection of $\mathrm{H} 2(\mathrm{H} 1)$, as implying that whether intervention had occurred (was reported) was more important than whether it was reported (had occurred).

We analyze the first difference of the logarithm of the exchange rate. This follows Baillie and Bollersev (1989) and others who have found unit roots in daily exchange rates. (1) $\Delta$ In $s_{i}=\alpha_{0}+\sum_{i=1}^{5} \alpha_{i} D O W_{t i}+\epsilon_{t}$ In equation (1), there are five dummy variables. $\mathrm{DOW}_{\mathrm{t} 1}=1$ if day $\mathrm{t}$ is a Monday, and $\mathrm{i}=$ 2,3,4,5 correspond to Wednesday, Thursday, Friday, and days before market holidays, respectively. As has been noted by McFarland, Pettit, and Sung (1982), Baillie and Bollersev (1989), and Hsieh (1988, 1989), daily exchange rates (and even their volatility) can be different for different days of the week. This may be due to variation in the volume of trading and in the flow of information.

(2) $\epsilon_{t} \mid \Omega_{t-1} \sim D\left(0, \sigma_{t}^{2}\right)$

(3) $\sigma_{t}^{2}=\beta_{0}+\beta_{1} \epsilon_{t-1}^{2}+\beta_{2} \sigma_{t-1}^{2}+\sum_{i=1}^{5} \beta_{2+i} D O W_{t}$

The conditional variance equation is modeled as $\operatorname{GARCH}(1,1)$, and we allow the conditional density D to be either normal or student-t. Bollersev (1987) discusses the estimation of this type of model. Bollersev (1986), Hsieh (1989), and Baillie and Bollersev (1989) conclude that the GARCH(1,1)-student-t formulation does better than its competitors in modeling daily exchange rate movements. 
We add dummy intervention variables disaggregated along several dimensions. For each currency (DM/\$ and Yen $/ \$)$, we define both buying and selling and classify intervention

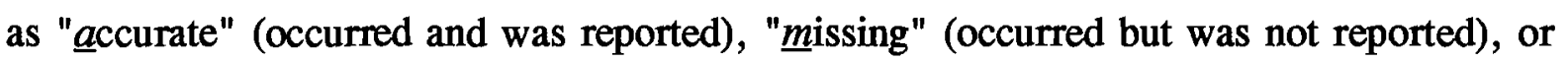
"fake" (did not occur but was reported).

Thus, to test $\mathrm{H} 1$ and $\mathrm{H} 2$, we modify equations (1) and (3) as follows:

$$
\begin{aligned}
& \text { (1') } \Delta \ln s_{t}=\alpha_{0}+\sum_{i=1}^{5} \alpha_{i} D O W_{i t}+\sum_{j=6}^{K} \alpha_{j} I_{t j}+\epsilon_{t} \\
& \left(3^{\prime}\right) \sigma_{t}^{2}=\beta_{0}+\beta_{1} \epsilon_{t-1}^{2}+\sum_{i=2}^{6} \beta_{2+i} D O W_{f i}+\sum_{j=6}^{K+1} \beta_{7+i}
\end{aligned}
$$

where the variable definitions are as described in table 1 . Testing $\mathrm{H} 1$ and $\mathrm{H} 2$ implies testing the restrictions that the coefficients on the variables for "accurate" and "missing," as well as on "accurate" and "fake," are equal, respectively.

\section{Results}

Table 2 reports the number of occurrences of each intervention measure. For the full sample periods, only 17 percent and 16 percent of actual U.S. intervention vis-à-vis the DM and yen, respectively, were reported in the foreign exchange column of The Wall Street Journal. This is lower than the percentages calculated by other researchers. The first subperiod (time 3), from February 23, 1987 through October 18, 1987, begins after the Louvre Accord and ends just prior to the stock market decline on October 19. Almost all U.S. intervention activity here consisted of buying dollars, either by selling DM or by selling yen. In contrast, from October 19, 1987 through February 19, 1990, most U.S. intervention 
vis-à-vis the DM or yen consisted of selling dollars. The final period saw limited U.S. intervention, with some tendency to sell DM (buy dollars in terms of DM) and buy yen (sell dollars for yen).

Table $3 \mathrm{a}$ reports the results of tests for the $\mathrm{GARCH}(1,1)$-student-t specification, for the inclusion of dummies, and for including intervention in the conditional mean equation. For the full sample period for both currencies, line 1 shows that the $\operatorname{GARCH}(1,1)$ specification improves on including only intercepts when the disturbance is assumed to be normally distributed. Line 2 indicates that the student-t distribution improves upon normality. For both currencies, specification tests suggest the joint addition of the five dayof-the-week variables (Monday, Wednesday, Thursday, Friday, and days before market holidays) to the conditional mean and conditional variance (line 5). ${ }^{8}$ Results for the subperiods generally confirm these interpretations. Except for the extremely short third sample period for the DM, tests of the GARCH(1,1)-student-t specification suggest its acceptance. However, day-of-the-week effects are not present for the DM $/ \$$ for the first and second subperiods.

Lines 6 through 9 of table 3a report the results of our main tests. Lines 6 and 7 test our two main hypotheses: H1) If intervention was reported, it does not matter if it occurred, and H2) If intervention occurred, it does not matter if it was reported. We reject $\mathbf{H} 1$ at the 0.05 level for the final subperiod for the Yen/\$. Lines 8 and 9 provide some perspective on this result by indicating the test statistics for the overall significance of reported intervention and of actual intervention, respectively. Contrary to the results of previous research, neither measure of intervention usually affects the $\mathrm{DM} / \$$ or Yen $/ \$$. Only for the final subperiod for 
the Yen $/ \$$ does intervention affect the conditional mean. Actual intervention matters (line 9) when entered as a single variable, imposing the restriction that whether or not the intervention is reported does not matter. Reported intervention also matters, if we are careful to distinguish between reports that are accurate and those that are not. However, the low frequency of intervention during this period qualifies these results.

Table $3 b$ reports test results for impacts of intervention on the conditional variance. For the full sample period, actual intervention affects the Yen/\$, and it does not matter if such intervention is reported. For the subperiods, we find more evidence for impacts of intervention. For the October 19, 1987 - February 19, 1990 subperiod for the DM/\$, intervention influences the variance and, importantly, we also reject $\mathrm{H} 2$, finding that the impact of actual intervention that was reported (A) differs from the impact of actual intervention that was not reported (M). However, we cannot reject $\mathrm{H} 1$ for this case.

For the same period as discussed above, we reject $\mathrm{H} 2$ for the Yen $/ \$$. If we restrict intervention that was reported to have the same impact as intervention that was not reported, we would conclude that actual intervention does not influence the conditional variance (line 9). Thus, in this case, actual intervention matters if we are careful to distinguish between whether or not it was reported.

The table 4 tabulations of coefficient estimates focus on the second subsample, for which we find impacts of intervention on the variance for both exchange rates. The significance of the day-of-the-week dummies is sensitive to specification. The conditional means of the $\mathrm{DM} / \$$ and $\mathrm{Yen} / \$$ are significantly higher (at the 10 percent level as measured by the $t$ statistic) on Thursdays only when accurate reports $(R)$ and missing reports $(M)$ are 
included in the former, and only when the aggregate of the two types of intervention $(\mathbf{R}+\mathbf{M})$ is included in the latter. The conditional mean is also significantly higher on Fridays, but is lower on days before market holidays for the Yen $/ \$$ when $R+M$ is included in the conditional variance. The conditional variance is higher for the $D M / \$$ only when $R$ and $M$ are included separately in the conditional variance equation, but is lower for the Yen/\$ only when $\mathbf{R}+\mathbf{M}$ is included in the conditional variance equation.

The first column of table 4 shows that the impact of accurate reports (A) is negative for the $\mathrm{DM} / \$$, while the impact of missing reports $(M)$ is positive. Although the individual $t$ statistics are not significantly different from zero at the 10 percent level, table $3 \mathrm{~b}$ reported that the two measures are jointly significant. The second column shows that the overall impact of actual intervention $(A+M)$ is positive. The third and fourth columns confirm this finding for the Yen/\$; accurate reports have a negative impact on the conditional variance, while missing reports $(M)$ have a positive impact.

\section{Conclusion}

A limited amount of previous research has compared actual U.S. central bank intervention with the newspaper reports of such activities. Using a GARCH(1,1)-student-t specification of the daily exchange rate process for the DM $/ \$$ and Yen $/ \$$, official U.S. intervention vis-a-vis the Deutschemark and yen, and The Wall Street Journal reports of U.S. intervention, we confirm previous findings that the impact of intervention seems to be sample dependent. We find that 1) except for the February 19, 1990 - September 5, 1991 subperiod for the Yen/\$, neither the distinction between accurate reports of intervention and false reports (given that intervention was reported) nor the distinction between accurate reports and 
missing reports (given that intervention occurred) is significant in terms of the conditional mean; 2) for October 19, 1987 through February 19, 1990, actual intervention influences the conditional variance for both exchange rates, and the impact depends on whether the intervention was reported; and 3) for the latter subperiod, intervention that was reported decreased the conditional variance for both currencies, while intervention that was not reported increased the conditional variance.

Compared to the results of previous research, our findings show that intervention has relatively little impact overall. One possible partial explanation is that we have recorded too few reports of intervention. Our response to this is to note that a relatively liberal coding of the reports may not be consistent with our desire to proxy for any informational asymmetries within the market. On one hand, viewing any difference between our reported intervention series and other researchers' series as measurement error could explain our finding that reported intervention does not affect exchange rates overall. On the other hand, the finding that actual intervention has no impact on exchange rates is not subject to this criticism. We investigated the possibility that including day-of-the-week effects may have influenced our results. ${ }^{9}$ We ran probits where the dependent variables are the intervention measures, either reported intervention (the sum of accurate and fake) or actual intervention (the sum of

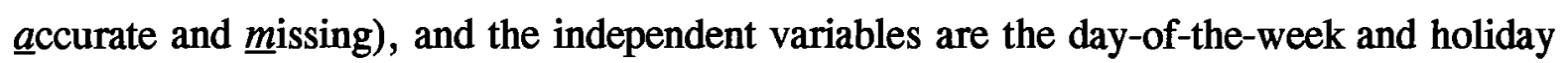
dummies, with an intercept. For no case is there any tendency for intervention either to occur or to be reported on any particular day of the week or on days before market holidays. 


\section{Footnotes}

1. These latter stock measures are utilized to test the portfolio balance theory of how intervention would affect exchange rates. For a recent empirical application, see Ghosh (1992).

2. There is no coherent view of what signaling means. For some, it means that there is a "consistent and proximate" relation between intervention and some future change in monetary policy (Klein and Rosengren [1991]). For others, it means that intervention influences exchange rates, given any portfolio balance effect (Ghosh [1992]).

3. Sterilization means that the removal of the dollars via the initial purchase is offset by the purchase of U.S. government securities of the same amount.

4. Humpage (1994) discusses the institutional aspects of U.S. intervention operations, focusing on the nexus between the Federal Reserve's actual transacting from its New York Desk and the Exchange Stabilization Fund of the U.S. Department of the Treasury. Todd (1992) details the historical evolution of the rationales for U.S. intervention operations.

5. See Dominguez and Frankel (1993, pp.72-73) and Humpage (1994, pp. 9-10).

6. The sample periods for the three investigations are roughly consistent: Klein (1993): January 1, 1985-December 31, 1989; Bonser-Neal and Tanner (forthcoming): January 1, 1985-December 31, 1989; this paper: August 6, 1985September 5, 1991 .

7. Earlier sample periods could not be analyzed due to the low number of occurrences of most of the categories of intervention.

8. The coefficient estimates indicate a "Thursday" effect. Since our day-ofthe-week dummies are aligned with day $t-1$, our Thursday effect is equivalent to others' Friday effects.

9. There has been no consistent treatment of these effects. Dominguez (1993) includes a full array of day-of-the-week and holiday dummies, but Dominguez and Frankel (1993) include no such dummies, and Bonser-Neal and Tanner (forthcoming) include only a dummy for holidays or weekends. 


\section{REFERENCES}

Baillie, Richard T. and Tim Bollersev. "The Message in Daily Exchange Rates: A Conditional Variance Tale," Journal of Business and Economic Statistics, vol. 7, no. 3, 1989, pp. 297-305.

Bollersev, Tim. "Generalized Autoregressive Conditional Heteroskedasticity," Journal of Econometrics, vol. 31, 1986, pp. 307-327.

Bollersev, Tim. "A Conditional Heteroskedastic Time Series Model for Speculative Prices and Rates of Return," Review of Economics and Statistics, vol. 69, 1987, pp. 542-547.

Bonser-Neal, Catherine and Glenn Tanner. "Central Bank Intervention and the Volatility of Foreign Exchange Rates: Evidence from the Options Market," Journal of International Money and Finance, forthcoming.

Dominguez, Kathryn M. "Does Central Bank Intervention Increase the Volatility of Foreign Exchange Rates?" National Bureau of Economic Research Working Paper No. 4532, November 1993.

Dominguez, Kathryn M. and Jeffrey A. Frankel. Does Foreign Exchange Intervention Work? Institute for International Economics, Washington, D.C., 1993.

Edison, Hali J. "The Effectiveness of Central-Bank Intervention: A Survey of the Literature after 1982," Special Papers in International Economics No. 18, Princeton University, July 1993.

Ghosh, Atish. "Is It Signalling? Exchange Intervention and the Dollar-Deutschemark Rate," Journal of International Economics, vol. 32, 1992, pp. 201-220.

Hsieh, David A. "The Statistical Properties of Daily Foreign Exchange Rates: 1974-1983," Journal of International Economics, vol. 24, 1988, pp. 129-145.

Hsieh, David A. "Modeling Heteroskedasticity in Daily Exchange Rates," Journal of Business and Economic Statistics, vol. 7, no. 3, July 1989, pp. 307-317.

Humpage, Owen F. "Institutional Aspects of U.S. Intervention," Economic Review, Federal Reserve Bank of Cleveland, vol. 30, no. 1, 1994, pp. 2-19.

Humpage, Owen F. and William P. Osterberg. "Intervention and the Foreign Exchange Risk Premium: An Empirical Investigation of Daily Effects," Global Finance Journal, vol. 3, no. 1, 1992, pp. 23-50. 
Hung, Juann H. "Noise Trading and the Effectiveness of Sterilized Foreign Exchange Intervention," Federal Reserve Bank of New York, Research Paper No. 9111, March 1991.

Klein, Michael W. "The Accuracy of Reports of Foreign Exchange Intervention," Journal of International Money and Finance, vol. 12, 1993, pp. 644-653.

Klein, Michael W. and Eric S. Rosengren, "Foreign Exchange Intervention as a Signal of Monetary Policy," New England Economic Review, Federal Reserve Bank of Boston, May-June 1991, pp. $39-50$.

McFarland James W., R. Richardson Pettit, and Sam K. Sung. "The Distribution of Foreign Exchange Price Changes: Trading Day Effects and Risk Measurement," Journal of Finance, vol. 37, 1982, pp. 693-715.

Osterberg, William P. and Rebecca Wetmore Humes. "The Inaccuracy of Newspaper Reports of U.S. Foreign Exchange Intervention," Economic Review, Federal Reserve Bank of Cleveland, vol. 29, no. 4, 1993, pp. 25-33.

Todd, Walker F., "Disorderly Markets: The Law, History, and Economics of the Exchange Stabilization Fund and U.S. Foreign Exchange Market Intervention," Research in Financial Services: Public and Private Policy, vol. 4, 1992, pp. 111-179. 
Table 1: Dummy Variable Definitions

\begin{tabular}{|c|c|}
\hline Name & Definition \\
\hline $\mathrm{DOW}_{\mathrm{t} 1}$ & equals 1 if day $t$ is a Monday \\
\hline $\operatorname{DOW}_{12}$ & equals 1 if day $t$ is a Wednesday \\
\hline $\mathrm{DOW}_{\mathrm{t}}$ & equals 1 if day $t$ is a Thursday \\
\hline DOW $_{\mathrm{t} 4}$ & equals 1 if day $t$ is a Friday \\
\hline $\mathrm{DOW}_{\mathrm{t}}$ & equals 1 if day $t$ is the day before a holiday \\
\hline $\mathbf{a - b}$ & equals 1 if U.S. actually bought dollars and was also reported to be doing so \\
\hline a-s & equals 1 if U.S. actually sold dollars and was also reported to be doing so \\
\hline $\mathbf{m}-\mathbf{b}$ & equals 1 if U.S. actually bought dollars but was not reported to be doing so \\
\hline m-s & equals 1 if U.S. actually sold dollars but was not reported to be doing so \\
\hline $\mathbf{f}-\mathbf{b}$ & equals 1 if U.S. was not buying dollars but was reported to be doing so \\
\hline f-s & equals 1 if U.S. was not selling dollars but was reported to be doing so \\
\hline A & equals 1 if U.S. was either buying or selling dollars and was reported to be \\
\hline $\mathbf{M}$ & equals 1 if U.S. was either buying or selling dollars but was not reported to be \\
\hline $\mathbf{F}$ & equals 1 if U.S. was neither buying nor selling dollars but was reported to be \\
\hline$A+F$ & equals 1 if U.S. was reported to be either buying or selling dollars \\
\hline $\mathbf{A}+\mathbf{M}$ & equals 1 if U.S. actually was either buying or selling dollars \\
\hline
\end{tabular}


Table 2: Frequencies of Intervention Measures

\begin{tabular}{||r|r|r|r|r||}
\hline \multicolumn{1}{|c|}{ Sample $\rightarrow$} & \multicolumn{1}{c|}{ Full } & \multicolumn{1}{c|}{ A } & \multicolumn{1}{c|}{ B } & \multicolumn{1}{c|}{ C } \\
\hline \hline DM/\$ & & & & \\
\hline N & 1486 & 160 & 574 & 377 \\
\hline a-b & 4 & 1 & 1 & 2 \\
\hline a-s & 29 & 1 & 26 & 1 \\
\hline m-b & 57 & 7 & 28 & 22 \\
\hline m-s & 101 & 4 & 77 & 7 \\
\hline f-b & 3 & 1 & 0 & 2 \\
\hline f-s & 4 & 1 & 2 & 0 \\
\hline Yen/\$ & & & & \\
\hline N & 1485 & 163 & 562 & 393 \\
\hline a-b & 10 & 3 & 6 & 0 \\
\hline a-s & 19 & 0 & 12 & 7 \\
\hline m-b & 55 & 22 & 33 & 0 \\
\hline m-s & 95 & 4 & 65 & 7 \\
\hline f-b & 1 & 0 & 1 & 0 \\
\hline f-s & 2 & 0 & 0 & 2 \\
\hline
\end{tabular}

Full sample: August 6, 1985-September 5, 1991(DM/\$) or

August 6, 1985-October 4, 1991(Yen/\$)
A: February 23, 1987-October 18, 1987
B: October 19, 1987-February 19, 1990
C: February 20, 1990-September 5, 1991
Source: Authors' calculations. 
Table 3a: Likelihood Ratio Tests for Model Specification (Intervention in the Mean)

\begin{tabular}{|c|c|c|c|c|c|}
\hline Sample $\rightarrow$ & & Full & A & B & $\mathrm{C}$ \\
\hline $\mathbf{D M} / \mathbf{\$}$ & d.f. & & & & \\
\hline 1) $\mathbf{H}_{0}: \beta_{1}=\beta_{2}=0$ & 2 & $134.28^{\mathrm{a}}$ & 0.44 & $38.75^{\mathrm{a}}$ & \\
\hline 2) Normality & 1 & $52.27^{\mathrm{a}}$ & 0.97 & $14.01^{\mathrm{a}}$ & \\
\hline 3) DOWs in mean & 5 & 6.15 & 3.90 & 8.83 & \\
\hline 4) DOWs in variance & 5 & $16.45^{\mathrm{a}}$ & 7.92 & 3.24 & \\
\hline 5) DOWs in both & 10 & $22.48^{\mathrm{a}}$ & 11.38 & 12.39 & \\
\hline 6) $\mathrm{H} 1: A=F$ & 1 & 1.81 & 0.01 & 0.49 & \\
\hline 7) $\mathrm{H} 2: \mathrm{A}=\mathbf{M}$ & 1 & 0.06 & 0.22 & 0.10 & \\
\hline 8) $A+F=0$ & 1 & 0.08 & 0.07 & 0.27 & \\
\hline 9) $A+M=0$ & 1 & 1.42 & 1.89 & 0.74 & \\
\hline \multicolumn{6}{|l|}{ Yen/\$ } \\
\hline 1) $\mathrm{H}_{0}: \beta_{1}=\beta_{2}=0$ & 2 & $100.56^{a}$ & & $81.01^{\mathrm{a}}$ & $24.80^{\mathrm{a}}$ \\
\hline 2) Normality & 1 & $152.18^{\mathrm{a}}$ & & $56.01^{\mathrm{a}}$ & $11.72^{\mathrm{a}}$ \\
\hline 3) DOWs in mean & 5 & $15.11^{\mathrm{a}}$ & & $14.07^{\mathrm{a}}$ & 6.99 \\
\hline 4) DOWs in variance & 5 & $24.54^{a}$ & & 4.64 & $12.25^{\mathrm{a}}$ \\
\hline 5) DOWs in both & 10 & $35.55^{\mathrm{a}}$ & & $20.14^{\mathrm{a}}$ & $16.60^{b}$ \\
\hline 6) $H 1: A=F$ & 1 & 0.03 & & 0.20 & $4.67^{\mathrm{a}}$ \\
\hline 7) $\mathrm{H} 2: \mathrm{A}=\mathbf{M}$ & 1 & 0.50 & & 0.07 & 0.36 \\
\hline 8) $A+F=0$ & 1 & 0.62 & & 2.03 & 0.22 \\
\hline 9) $A+M=0$ & 1 & 0.54 & & 2.65 & $3.70^{\mathrm{b}}$ \\
\hline
\end{tabular}

A: February 23, 1987-October 18, 1987

B: October 19, 1987-February 19, 1990

C: February 20, 1990-September 5, 1991

d.f.: degrees of freedom for the likelihood ratio test

a : significant at the 0.05 level.

b : significant at the 0.10 level.

Source: Authors' calculations. 
Table 3b: Likelihood Ratio Tests for Model Specification (Intervention in the Variance)

\begin{tabular}{|c|c|c|c|c|c|}
\hline Sample $\rightarrow$ & & Full & A & B & $\mathrm{C}$ \\
\hline DM/\$ & d.f. & & & & \\
\hline 6) $\mathrm{H} 1: \mathrm{A}=\mathrm{F}$ & 1 & 0.06 & 0.42 & 1.99 & \\
\hline 7) $\mathrm{H} 2: \mathrm{A}=\mathrm{M}$ & 1 & 1.76 & 0.11 & $4.45^{\mathrm{a}}$ & \\
\hline 8) $A+F=0$ & 1 & 1.50 & 0.02 & 0.64 & \\
\hline 9) $\mathbf{A}+\mathbf{M}=0$ & 1 & 0.13 & 0.17 & $2.75^{\mathrm{b}}$ & \\
\hline \multicolumn{6}{|l|}{ Yen/\$ } \\
\hline 6) $\mathrm{H} 1: A=F$ & 1 & 0.10 & & 0.01 & 0.36 \\
\hline 7) $\mathrm{H} 2: \mathrm{A}=\mathrm{M}$ & 1 & 0.69 & & $6.35^{\mathrm{ac}}$ & 1.48 \\
\hline 8) $\mathrm{A}+\mathrm{F}=0$ & 1 & 0.46 & & 0.18 & 0.35 \\
\hline 9) $A+M=0$ & 1 & $4.56^{\mathrm{a}}$ & & 2.51 & 0.23 \\
\hline
\end{tabular}

A: February 23, 1987-October 18, 1987

B: October 19, 1987-February 19, 1990

C: February 20, 1990-September 5, 1991

d.f.: degrees of freedom for the likelihood ratio test

${ }^{\text {a }}$ : significant at the 0.05 level.

${ }^{\mathrm{b}}$ : significant at the 0.10 level.

$c$ : 1 degree of freedom

Source: Authors' calculations. 
Table 4: Estimates for Equations (1') and ( $\left.3^{\prime}\right)$, Subsample B, Lines 7 and 9, Table $3 b$

\begin{tabular}{|c|c|c|c|c|}
\hline sample $\rightarrow$ & $\mathrm{DM} / \$$ & $\mathrm{DM} / \$$ & Yen $/ \$$ & Yen $/ \$$ \\
\hline \multirow[t]{2}{*}{$\alpha_{0}$} & -0.01917 & -0.0133 & 0.1378 & 0.1596 \\
\hline & $(0.0611)$ & $(0.0630)$ & $(0.4508)$ & $(0.4179)^{*}$ \\
\hline \multirow[t]{2}{*}{$\beta_{0}$} & 0.02993 & 0.0143 & 6.463 & 2.8360 \\
\hline & $(0.0647)$ & $(0.0750)$ & $(6.267)$ & $(6.2476)$ \\
\hline \multirow[t]{2}{*}{$\beta_{1}$} & 0.0853 & 0.0687 & 0.0704 & 0.0536 \\
\hline & $(0.0311)^{*}$ & $(0.0294)^{*}$ & $(0.0357)^{*}$ & $(0.0276)^{*}$ \\
\hline \multirow[t]{2}{*}{$\beta_{2}$} & 0.8359 & 0.8849 & 0.8429 & 0.8766 \\
\hline & $(0.0507)^{*}$ & $(0.0430)^{*}$ & $(0.0488)^{*}$ & $(0.0433)^{*}$ \\
\hline \multirow[t]{2}{*}{$\alpha_{\text {Mon }}$} & -0.0138 & -0.0145 & -0.6275 & -0.5556 \\
\hline & $(0.0869)$ & $(0.0901)$ & $(0.6127)$ & $(0.5940)$ \\
\hline \multirow[t]{2}{*}{$\alpha_{\text {Wed }}$} & -0.0622 & 0.0760 & -0.5287 & -0.2902 \\
\hline & $(0.0855)$ & $(0.0831)$ & $(0.6158)$ & $(0.6104)$ \\
\hline \multirow[t]{2}{*}{$\alpha_{\mathrm{Thu}}$} & 0.1447 & 0.1257 & 0.8930 & 0.9975 \\
\hline & $(0.0862)^{*}$ & $(0.0880)$ & $(0.6175)$ & $(0.6047)^{*}$ \\
\hline \multirow[t]{2}{*}{$\alpha_{P_{i}}$} & 0.0233 & 0.0164 & 0.8368 & 1.3253 \\
\hline & $(0.0851)$ & $(0.0846)$ & $(0.6780)$ & $(0.6467)^{*}$ \\
\hline \multirow[t]{2}{*}{$\alpha_{\text {Hol }}$} & 0.1838 & 0.1781 & -2.0369 & -2.2872 \\
\hline & $(0.1485)$ & $(0.1405)$ & $(0.8787)^{*}$ & $(0.8035)^{*}$ \\
\hline \multirow[t]{2}{*}{$\beta_{\text {Mon }}$} & -0.0270 & -0.0051 & -12.2793 & -7.8070 \\
\hline & $(0.1015)$ & $(0.1141)$ & $(8.4899)$ & $(8.6777)$ \\
\hline \multirow[t]{2}{*}{$\beta_{\mathrm{wed}}$} & -0.0483 & -0.0549 & -5.746 & 3.6129 \\
\hline & $(0.1137)$ & $(0.1276)$ & (11.8208) & $(12.2805)$ \\
\hline \multirow[t]{2}{*}{$\beta_{\text {Tuu }}$} & 0.0393 & 0.0695 & -6.357 & -4.3623 \\
\hline & $(0.0925)$ & $(0.1104)$ & (8.7412) & $(9.3509)$ \\
\hline \multirow[t]{2}{*}{$\beta_{\mathrm{Fi}}$} & -0.0014 & -0.0221 & 6.470 & 8.1465 \\
\hline & $(0.0899)$ & $(0.1018)$ & (9.0696) & $(9.7127)$ \\
\hline
\end{tabular}


Table 4 (continued)

\begin{tabular}{||l|l|l|l|l||}
\hline$\beta_{\mathrm{Hol}}$ & 0.1344 & 0.1089 & -8.4893 & -12.0079 \\
\hline $\mathrm{A}$ & $(0.0809)^{*}$ & $(0.0749)$ & $(5.1302)$ & $(5.5364)^{*}$ \\
\hline & -0.0637 & & -3.7351 & $(6.2749)$ \\
\hline $\mathrm{M}$ & $(0.0528)$ & & 10.9650 & \\
\hline & 0.0502 & & $(5.2077)^{*}$ & \\
\hline $\mathrm{RM}$ & $(0.0307)$ & 0.0217 & & 6.0296 \\
\hline $1 / v$ & & $(0.0203)$ & 0.0963 & $(3.0353)^{*}$ \\
\hline & & $(0.0068)^{*}$ & $(0.0135)^{*}$ & 0.1754 \\
\hline $\mathrm{m}_{3}$ & 0.0478 & -0.1047 & -0.0059 & $(0.0001)^{*}$ \\
\hline $\mathrm{m}_{4}$ & $(0.0001)^{*}$ & 3.6999 & 4.8643 & 0.011793 \\
\hline \hline
\end{tabular}

* significant at the 0.10 level.

Note: Standard errors are in parentheses beneath coefficient estimates.

Source: Authors' calculations. 